\title{
Editorial
}

\section{The end of the pandemic, new opportunities to meet?}

\section{Introduction}

When writing this editorial in the middle of February 2022, the side meetings to the yearly meeting of the United Nations Statistical Commission (UNSC) have already started. Though the Omikron variant of the COVID-19 virus seems to cause lesser serious illness, these side meetings are still organized in a virtual webinar format, and also the main UNSC meeting will be held in a virtual format. With taking over as the most dominant COVID virus variant, Omikron allows more and more people to travel again, restricts working from home and the intention for organizing in-person meetings and conferences is shaping up again. When you read this editorial, in mid-March, it also will be clear if the 2-yearly IAOS conference from 26-28 April 2022 to be held in Krakow (Poland) will be - as planned - an in-person meeting. The UNSC and its side meetings as well as the many other international conferences are for official statistics - like international meetings are for many other fields - very important events that facilitate intensive networking and the opportunity to exchange views. An in-person meeting in Krakow would allow us to again/finally - after two years of travel restrictions meet in-person the colleagues in Official Statistics. I am looking forward to meeting old friends again.

During the last two 'pandemic' years with all its restrictions, the community of official statisticians has surely not been invisible or been unable to work and act when needed. On the opposite, virtual (and partly hybrid) conferences like the UNSC and its many side meetings in 2021, the 2021 UN World Data Forum (UN-WDF), the 2021 ISI World Statistics Conference (WSC), the 2020 and 2021 Paris 21 Annual Meetings, just to mention a few larger conferences, and the many smaller conferences attracted because of its webinar format probably even more colleagues to participate than when it would have been a traditional conference.
The virtual or hybrid conference format causes an advantage for those colleagues that otherwise because of costs would not have been able to attend, moreover, it probably saved a lot of traveling time (and money) for the people and organizations involved. These virtual meetings, webinars, etc. have filled up days and weeks in my agenda, which makes me assume that the community of official statistics has been even more active and engaged these last two years than before and that this was especially thru for the periods between the dates of International conferences.

Having to work from home and missing the daily in-person contacts with colleagues and more, in general lacking the so useful input from informal meetings held in corridors, cafeteria and copy rooms, made (short) webinars around a specific theme or a virtual training also very popular. The relative ease in registering and attending has facilitated this formula to become a success. A collaborative initiative ${ }^{1}$ by the editors of five ISI-related and leading international journals on (official) statistics and publishers of these journals, of a workshop" on 'Writing manuscripts for Offical Statistics journals' attracted over 450 registrations. Each of the three sessions of each two hours of this workshop counted over 200 active participants.

With the experiences from the many and so effective virtual meetings and webinars in mind but also with the pleasant memories and high expectations of the earlier in-person meetings, I hope we can - when the pandemic is over - keep the best of both in our life as part of the network of official statistics.

\footnotetext{
${ }^{1}$ International Statistical review (ISI), Statistical Journal of the IAOS IAOS), Journal of Official Statistics (Statistics Sweden) Journal of Survey Methodology (Statistics Canada), Survey Statistician (IASS/IBGE, Brazil), Wiley, IOSPRESS.

${ }^{2}$ Workshop 'Writing manuscripts for Official Statistics journals: Guidelines for practitioners and researchers'. 8, 10, and 15 February 2022.
} 


\subsection{Why professional independence is a foundation of modern society: A very specific webinar organized by the IAOS}

In 2021 the book 'Why INEGI? The Saga of a Mexican Institution in Search of the Truth', by Mario Palma, ${ }^{3}$ was published. On this occasion, on the 29th of June a webinar with as title 'The role of National Statistical Offices in society and why professional independence is its foundation' was organized by INEGI, ISI, and IAOS. Speakers were Julio Santaella Castell, President of INEGI, Mario Palma Rojo, former IAOS President and former Governing Board of INEGI, Hermann Habermann, former US Chief Statistician and UNSD Director, John Pullinger, IAOS President and former UK National Statistician, and Misha Belkindas, founder of Open Data Watch and IAOS President-Elect. The webinar was hosted by Angela Me, Chief of Research and Trend Analysis Branch, UN Office on Drugs and Crime.

In this issue of the Journal Mario Palma in his article 'On Professional Independence,' elaborates on the issue of professional independence in official statistics. On the occasion of the publication of the book, and complementing this article, Hermann Habermann, ${ }^{4}$ engaged with Mario Palma in a dialogue on the book and in more general how to build a trustful statistical institute.

\subsection{Large international projects as important stimuli for the development and innovation in statistics: the example of the 50x2030 Initiative}

The UNSC, the main yearly event for official statistics, is an important gauge for current and future developments in official statistics. The meeting combines discussions and reflections on ongoing projects with touching on important new developments and initiatives. Conclusions are drawn from the discussions, intentions formulated, and plans agreed upon. Many of these impact - as commitments as well as in concrete results of better harmonized statistical information the work of the national statistical institutes and international organizations. Through its inclusive nature and relatively open meeting structure the UNSC and its side meetings also facilitate an effective exchange of experiences between the different statistical systems, on a global and regional scale. It combines discussions on

\footnotetext{
${ }^{3}$ Former IAOS President and former member of the Governing Board of INEGI, Mexico.

${ }^{4}$ Former US Chief Statistician and former UNSD Director.
}

governance, ethics, etc in official statistics organizations with more technical meetings and workshops. More deep reflection and exchange of experiences on methodological and technological issues can be positioned in side-meetings, though, these are predominantly done in international more 'scientific' conferences, like the ISI WSC and UN-WDF, and especially in international workshops and task force meetings organized under the remits of the UNSD or International Statistical Organizations.

International statistical projects, organized by cooperating international organizations with the involvement of a large number of regions as well as individual countries require - to be successful - the support of the international statistical community. Such large projects as initiated and monitored by the UNSC during the last couple of years are for example the International Price Comparison Project (ICP), the revision of the System of National Accounts (SNA), and the methodological and technological projects under the umbrella of the High-Level Group on the Modernisation of Statistics (HLG-MOS).

In 2010 the UNSC - considering the lack of the capacity of many developing countries to even produce and report on a minimum set of agricultural data necessary to monitor national trends or inform the international development debate - supported the initiation of the Global Strategy on Agricultural and Rural Statistics (GSARS). ${ }^{5}$ This large international project is ranked very high on the list of global statistical development initiatives and projects. The project aimed the coordinated international action to counteract the decline in the quality of agricultural statistics. It offered a variety of actions, projects, and initiatives varying from identification of a minimum set of core data for countries and the production of these data, promoting the integration of agricultural statistics into national systems, supported by capacity building efforts and a global research program for developing methodologies and tools. The AGRISurvey ${ }^{6}$ methodology, which combines an annual core module on production that is collected every year and several rotating modules collected periodically, is one of the outputs of the Global Strategy.

With the adoption of the Sustainable Development Goals Indicator Framework by the UNSC in 2016 and

\footnotetext{
${ }^{5}$ UN Statistical Commission, 41 session: Global Strategy to Improve Agricultural and Rural Statistics Report of the Friends of the Chair on Agricultural Statistics.

${ }^{6}$ AGRISurvey: Agricultural Integrated Survey Program. https:// www.fao.org/in-action/agrisurvey/en/.
} 
the General Assembly of the UN in $2017,{ }^{7}$ it was revealed that there still was a huge gap in agricultural and food statistics to fulfill the ambitions set by the General Assembly for monitoring of the agricultural, environmental and food-related SDG's. A multi-partner program has been set up by the WorldBank, the Food and Agricultural Organization (FAO), and the International Fund for Agricultural Development (IFAD), of importance and size ${ }^{8}$ that makes it a truly global project in statistical development. This 50x2030 Initiative aims to close the agricultural data gap by addressing current shortcomings in the quality and availability of agricultural data and by transforming country data systems in 50 countries in Africa, Asia, the Middle East and Latin America by 2030 .

It is a great honor to present in this issue the 50x2030 Initiative in seven individual articles, proceeded by a guest editorial. Each of the contributions focuses on a specific aspect ranging from the backgrounds to concrete outputs in specific countries. The 11th discussion on the SJIAOS discussion platform is also dedicated to statements around this global statistical development project.

Next to the already mentioned topics, this issue covers a lot of other themes. An interview with Misha Belkindas, the current president of the Executive Committee of the IAOS opens, followed by a Covid related article. The issue also contains the first set of manuscripts stemming from the recent ISI World Statistics Conference, on combining information from statistical registers and surveys in a population census context, two more articles on land cover and the agricultural census, and six manuscripts covering a diversity of methodological developments.

\section{The manuscripts in this issue in some more detail}

The president of the International Association for Official Statistics (IAOS) is elected every uneven year. In this issue of the Journal the incumbent IAOS president for the period 2021-2023, Misha Belkindas, is interviewed. After two years as president-elect (2019-21), Misha Belkindas took over during the ISI WSC 2021 in The Hague, as IAOS president from John Pullinger, and

\footnotetext{
${ }^{7}$ The global indicator framework was adopted by the UN General Assembly on 6 July 2017 and is contained in the Resolution adopted by the General Assembly on Work of the Statistical Commission pertaining to the 2030 Agenda for Sustainable Development (A/RES/71/313).

${ }^{8}$ Planned for a period of 10 years with an estimated cost of US $\$ 500$ million.
}

at the same time during the IAOS General Assembly Dominik Rozkrut was selected to follow Misha Belkindas as the president-elect (2021-23). In this interview, we learn more about Misha's background, his experiences with Official Statistics, and his plans as president of the IAOS.

\subsection{The impact of COVID-19}

Katharina Irimata and Paul Scanlon report in 'The Research and Development Survey (RANDS) during COVID-19' on the use of the National Center for Health Statistics (NCHS) Research and Development Survey (RANDS) for reporting on the pandemic and the associated methodological survey design decisions including the adaptation of question evaluation approaches and calibration of panel weights. The expansion of the RANDS platform and ongoing methodological research allowed the NCHS to report timely information about COVID-19 in the United States. From a methodological perspective, it demonstrated the use of recruited panels for reporting national health statistics.

\subsection{The governance of statistics}

In September 2021 the book 'Why INEGI? The Saga of a Mexican Institution in Search of the Truth', by Mario Palma, Former IAOS President and former member of the Governing Board of INEGI, was published. In his article 'On Professional Independence,' Mario Palma elaborates - based on his book - on the issue of professional independence in official statistics through the analysis of the basic tenets that inform its raison d' etre, the main threats against it, and the possible measures NSO's can promote to protect it. The manuscript presents some cases, both from the past and present, where governments from different countries have intervened against or attempted to interfere in the work of their national statistical offices, undermining the integrity of official statistical data for the benefit of political interests. The process of institutional autonomy of the National Institute of Statistics and Geography of Mexico (INEGI) is examined as a case study of the ways NSOs can promote the protection of their professional independence.

Complementing this article, Hermann Habermann, Former US Chief Statistician and former UNSD Director, has engaged with Mario Palma in a very interesting dialogue 'Interview with Mario Palma on his book: Why INEGI? The Saga of a Mexican Institution in Search of the Truth'. This interview gives interesting insights into the role and responsibilities of national statistical offices, especially from the perspective of Mexican of- 
ficial statistics and the motives and arguments by Mario Palma to write this book.

\subsection{0 by 2030 Initiative special section}

The 50x2030 Initiative to close the agricultural data gap is a multi-partner program that addresses current shortcomings in the quality and availability of agricultural data by transforming country data systems in 50 countries in Africa, Asia, the Middle East and Latin America by 2030 .

In the introduction to this section on this initiative 'Guest Editorial; Closing the data gap in agriculture through sustainable investment in the data value chain: Realizing the vision of the 50x2030 Initiative' Sydney Gourlay, Vasco Molini and Alberto Zezza introduce the backgrounds for this initiative as well the seven specific articles. The background relates to the limited ability of especially African and Asian countries to report on agricultural SDG indicators, and consequently the lack of good quality and recent data for the concerned SDGs. Moreover, this situation of lacking appropriate data is also a manifestation of a deeper problem: many low- and lower-middle-income countries do not have well-functioning data systems to generate and use the data needed to make improved programmatic investments and policy decisions. In the guest editorial, the seven articles in this section are introduced in more detail. An appendix to this introduction contains a list of publications of the 50x2030 Initiative.

\subsection{Other agricultural statistics}

In the article 'Automatic Extraction of Land Cover Statistics from Satellite Imagery by Deep Learning' Diego Zardetto, Eleonora Bernasconi, Fabrizio De Fausti, Francesco Pugliese and Monica Scannapieco address the challenge of producing fully automated land cover estimates from satellite imagery through Deep Learning algorithms. To produce these estimates they used a tile-based, classify and count design, a cutting edge Convolutional Neural Network model to implement the classification engine of the system. After testing and validating their system on Sentinel 2 images, the results were analyzed against a pseudo ground truth based on land cover information from the flagship European projects CORINE and LUCAS. The analysis shows that the automatically produced land cover estimates are in good agreement with the pseudo ground truth and that this supports the segmentation ability of the system. The authors conclude that their project com- pared to traditional projects like CORINE and LUCAS, is remarkably cheaper in producing, delivers timely and frequent land cover statistics and goes well beyond the NUTS 2 level for small area estimates. Finally, they underline also the quality of the maps generated to be used in cartography projects as an agile first level tool for map update or change detection purposes.

Jairo Castano, Adriana Neciu in 'Midterm review of the 2020 round of censuses of agriculture', report on the results of an online survey on the 2020 round of the World Programme for the Census of Agriculture (WCA 2020), that was sent to all UN member countries in early 2020. The main findings show that an increasing number of countries are shifting their census methodologies from classical to modular approaches and combining field enumeration with the use of administrative registers. It also shows how CAPI is overtaking PAPI as the main data collection mode and how a growing number of countries are relying on the use of new technologies such as CAWI, CATI, GIS and interactive online databases. A large number of countries postponed their censuses at least once due to lack of funds and the situation even got less positive due to the impact of the COVID-19 pandemic on most census operations.

\subsection{Population and housing census/social statistics}

The second section in this issue deals with the topic of 'Building statistical registers in countries with no administrative population registers'. The three manuscripts in this section are based on the contributions to the 2021 ISI World Statistics Conference (The Hague) Invited Paper Session (IPS) with the same title. In his introduction to this section, Jean-Michel Durr describes different directions in which countries are developing the use of administrative sources for their statistical production as well as to transform their population and housing census in either a fully register-based census or a census combining registers and surveys. From this IPS the following three articles in the section present the experience of France(Jean-Michel Durr, Olivier Haag, Francoise Dupont, Olivier Lefebre, 'Setting up statistical registers of individuals and dwellings in France: approach and first steps'), New Zealand (Mathew Page, Clara Eatherly, Christine Bycroft, 'A Statistical Person Register in New Zealand: Progress and challenges') and Canada (Julie Trépanier, 'The Canadian experience of building a privacy-responsible integrated statistical register infrastructure').

\subsection{Other themes}

Six more manuscripts discuss very different issues, 
varying from SDG Progress assessment to Machine Learning, Web Scraping, and Statistical Algorithms.

Arman Bibarbakhtnia in 'SDG Progress Assessment; comparing apples with what?' Reflects on a selected number of metrics developed by international organizations for measuring progress towards the Sustainable Development Goals (SDGs). The author states that the analysis shows that inconsistency in results concerning the progress of countries in measuring the SDGs is more likely to be driven by different interpretations of concepts and not on methodologies. From this perspective, he concludes that for a harmonized assessment of the progress in SDG measuring the harmonization of concepts should have priority. To achieve this the paper provides a set of principles for orchestrating SDG progress assessment efforts across international organizations.

In their contribution 'Big Data Adoption in Official Statistics: Challenges, Opportunities and Determinants', the authors Christopher A. Moturi and Allan Gather Wairumu assess the adoption of Big Data in research institutes in Kenya. For this, they collected information from 64 data practitioners based in 24 research institutes. Core in the paper is the identification of the determinants of the adoption of Big Data in statistics. A Technology Adoption Model (TAM) is developed for predicting the adoption. The authors conclude that there are immense opportunities for Big Data in statistics if the associated risks and challenges are addressed and the identified key determinants are prioritized to promote the adoption.

New technologies have created an exponential increase or 'data explosion' in data generation. These Big Data sources contribute to the reduction of the response burden and especially the cost of data collection. In their manuscript 'Web scraping technique for producing Iranian consumer price index' Ayoub Faramarzi, Reza Hadizadeh, Saeed Fayyaz, Sohrab Sajadimanesh, and Abbas Moradi report on the use of web scraping technique to extract the daily prices of the food and drinks products to replace them with conventional prices which had been used for price indices. The authors state that these sorts of new datasets allow a more rapid calculation of the indices for smaller time scales like weekly or daily basis in comparison to the conventional approach which is possible only on monthly basis. Findings revealed that the web scraping technique can be applied as an effective alternative to conventional methods for CPI.

An application of Machine Learning to Big data is described by Rani Noorani, Jimmy Nickledon, Eko
Rahmadia, and Nugroho Yudho in their contribution 'New Recommendation to Predict Export Value Using Big Data and Machine Learning Technique'. The manuscript aims to develop and select an AIS indicator to predict the monthly export value in Indonesia via an innovative approach using Seasonal ARIMA and Artificial Neural Network (ANN) methods to forecast the value of Indonesia's exports, aiming also to reduce the publicity lags between the current period and the published publication on monthly export values. Considering that ANN requires high computational costs to obtain optimal parameters they introduce a Genetic Algorithm (GA) for increasing ANN accuracy. The authors report on the successful established five indicators to be used as predictors in the forecasting model.

The group of authors of 'A Quality Framework for Statistical Algorithms' Wesley Yung, Siu-Ming Tam, Bart Beulens, Hugh Chipman, Florian Dumpert, Gabrielle Ascani, Fabiana Rocci, Joep Burger, and InKyung Choi) represent the 2019 launched project within the High-Level Group for the Modernisation of Official Statistics (HLG-MOS) to integrate machine learning (ML) into the official statisticians'toolbox. One of the objectives of this project is to address the potential loss of transparency from using "black-boxes" and the need to develop a quality framework. One of the main outputs of this HLG-MOS project is a Quality Framework for Statistical Algorithms (QF4SA). This Quality Framework does not replace existing quality frameworks; it complements them. As the QF4SA targets intermediate outputs and not necessarily the final statistical output, it should be used in conjunction with existing quality frameworks to ensure that high-quality outputs are produced. This paper presents the QF4SA, as well as some recommendations for NSOs considering the use of machine learning in the production of official statistics.

In the final manuscript in this section, Jitendra Sinha describes the effects of unemployment and inflation on output growth. His article 'Economic Impact of Unemployment and Inflation on Output Growth in Bihar during 1990-2019' uses time-series data to show how physical capital expansion in terms of infrastructure development along with skill development to provide employment opportunities to the youth appears to be the major determinant of boosting the potential productivity of physical and human capital and affecting positively the economic growth. The author concludes that the results indicate that there are benefits from an increased supply and improvement in the quality of physical capital. This increases labor productivity as well as investment in human capital. 
Translating into policy recommendations, the article recommends that Bihar makes large-scale investments in infrastructure and skill development and carry-on renewal at opportune moments to keep steady the positive trend of economic growth over the years.

I wish you pleasant readings of these interesting articles.

\section{SJIAOS discussion platform}

In August 2019 the Statistical Journal of the IAOS launched the online platform for discussion on topics of significant relevance for official statistics (www.official statistics.com) as part of the SJIAOS website. The discussion platform invites them to contribute to important discussions at a time of their choosing. With each release of an issue of the Statistical Journal, a new discussion topic is launched via a leading article or based on a section in the Journal. Each discussion runs for about a year and is closed with a concluding commentary by the article author(s).

This issue presents concretely the closing article on the 4th discussion on prerelease access to official statistics. Andreas Georgiou provides in 'Pre-release access to official statistics is not consistent with professional ethics' - some additional reflections', a short summary of the main messages of his original article ${ }^{9}$ as published in (Volume 36, (2020) Nr. 2), but mostly focuses on some additional reflections on the statements the discussion invited readers to react.

\subsection{Opening of the 11th discussion Large international projects on the development of official statistics, the 50x2030 Initiative as an example}

With the release of this issue of the Journal (March 2022), also the 11th discussion will be opened. This discussion will be inviting you to comment on a set of statements concerning the $50 \times 2030$ Initiative, as presented in this issue via seven manuscripts and a guest editorial. For more information about the statements and how to react see the introduction to the 'SJIAOS Discussion Platform' at the end of this issue.

Several other discussions are still also online on the SJIAOS Discussion platform (www.officialstatistics.

\footnotetext{
${ }^{9}$ Georgiou, A. 2020. Prerelease Access to Official Statistics is not Consistent with Professional Ethics. Journal of Official Statistics. Vol. 36, Issue 2. Available from: https://content.iospress.com/articles/ statistical-journal-of-the-iaos/sji200620.
}

com). For more information about the statements and how to react see the introduction to the 'SJIAOS Discussion platform' at the end of this issue.

\section{Some words about the next issues (Volume 38 (2022), Nr. 2, Vol. 38 (2022, Nr. 3)}

The next two issues of the journal are already in full preparation.

The June 2022 issue (Vol. 38 (2022), Nr. 2) will publish manuscripts based on papers from the 2021 ISI World Statistics Conference (The Hague). Also, the 2021 Bern UN World Data Forum (UN WDF) might result in some contributions. For the September 2022 issue (Vol. 38 (2022), Nr. 3) work is ongoing for a series of articles from members of the Committee for the Coordination of Statistical Activities (CCSA). This series of manuscripts by representatives of International Statistical Organizations will cover a variety of themes relevant to these organizations. For December (Vol. 38 (2022), Nr. 4) a diversity of manuscripts is expected among them several based on papers from the 2022 IAOS Conference that will be held in April in Krakow Poland. Participants are invited to reflect from the start of their preparation for the conference on a possible submission of their manuscript for consideration in the Statistical Journal. Beyond these issues with a diversity of manuscripts, there is a special issue planned for one of the first issues in 2023 on the 'History of Official Statistics'. The guest editorial team for this issue is in search of authors and relevant manuscripts, so, do not hesitate to inform me when you have a manuscript or idea for a manuscript for this special. (pevssjiaos@gmail.com). In the upcoming IAOS conference in Krakow in April 2022 , this theme will be also touched on in several sessions.

Of course there are always slots for other manuscripts; authors are kindly invited to submit their manuscripts to:

https://www.iospress.nl/journal/statistical-journal-ofthe-iaos/?tab=submission-of-manuscripts.

Pieter Everaers

Editor-in-Chief

Februari 2022

Statistical Journal of the IAOS

E-mail: pevssjiaos@gmail.com 